\title{
Storage effects on quantity and composition of dissolved organic carbon and nitrogen of lake water, leaf leachate and peat soil water
}

Marlen Heinz, Dominik Zak

DOI

10.1016/j.watres.2017.11.053

Original publication date

27 November 2017 (Available online)

\section{Document version}

Accepted manuscript

Published in

Water Research

\section{Citation (Vancouver)}

Heinz M, Zak D. Storage effects on quantity and composition of dissolved organic carbon and nitrogen of lake water, leaf leachate and peat soil water. Water Research. 2018;130:98-104. 
1 Storage effects on quantity and composition of dissolved organic carbon and nitrogen of lake water, leaf leachate and peat soil water

Heinz, Marlen ${ }^{\mathrm{a}, *} ;$ Zak, Dominik ${ }^{\mathrm{a}, \mathrm{b}, \mathrm{c}}$

a Department of Chemical Analytics and Biogeochemistry, Leibniz-Institute of Freshwater Ecology and Inland Fisheries (IGB), Müggelseedamm 301, 12587 Berlin, Germany

7 baculty of Agriculture and Environment, Landscape Ecology and Site Evaluation, University of

8 Rostock, Justus-von-Liebig-Weg 6, 18059 Rostock, Germany

$9{ }^{\mathrm{C}}$ Department of Bioscience, Aarhus University, Vejlsøvej 25, 8600 Silkeborg, Denmark

*Corresponding author. Present address: Institute for Ecological Chemistry, Plant Analysis and Stored Product Protection, Julius Kühn-Institut, Federal Research Centre for Cultivated Plants, Königin-Luise-Str. 19, 14195 Berlin, Germany

14 E-mail adress: marlen.heinz@julius-kuehn.de

\section{Abstract}

This study aimed to evaluate the effects of freezing and cold storage at $4^{\circ} \mathrm{C}$ on bulk dissolved organic carbon (DOC) and nitrogen (DON) concentration and SEC fractions determined with size exclusion chromatography (SEC), as well as on spectral properties of dissolved organic matter (DOM) analyzed with fluorescence spectroscopy. In order to account for differences in DOM composition and source we analyzed storage effects for three different sample types, including

22 a lake water sample representing freshwater DOM, a leaf litter leachate of Phragmites australis representing a terrestrial, 'fresh' DOM source and peatland porewater samples. According to our findings one week of cold storage can bias DOC and DON determination. Overall, the

25 determination of DOC and DON concentration with SEC analysis for all three sample types were 26 little susceptible to alterations due to freezing. The findings derived for the sampling locations 27 investigated here may not apply for other sampling locations and/or sample types. However, 
28 DOC size fractions of formerly frozen samples should be interpreted with caution when sample

29 concentrations are high. Alteration of some optical properties (HIX and SUVA 254 ) due to freezing

30 were evident, and therefore we recommend immediate analysis of samples for spectral

31 analysis.

32 Keywords: freezing, cold storage, size exclusion chromatograpy (SEC), dissolved organic 33 nitrogen (DON), dissolved organic carbon (DOC) 


\section{Introduction}

Dissolved organic matter (DOM) is a mixture of various soluble compounds differing in their molecular weight, structure and complexity (Leenheer and Croué, 2003). The composition of DOM can determine its bioavailibility (Parr et al. 2015, Petrone et al. 2009) and consequently strongly influences the fate and persistance of DOM in aquatic ecosystems. Changes of environmental conditions such as alterations of $\mathrm{pH}$ or ion density, as well as freezing and thawing can affect the structure of these compounds (Dryer et al., 2008; Giesy and Briese, 1978; Pace et al., 2012) and as a consequence thereof, also DOM concentration and the optical properties of chromophore DOM (Fellman et al., 2008; Gao et al., 2015; Peacock et al., 2015; Spencer et al., 2007; Thieme et al., 2016). Acidification can be applied to arrest biological activity during cold storage (Schneider-Zapp et al., 2013), and is a common sample preservation method for later analysis of bulk dissolved organic carbon (DOC). However, for subsequent analysis with size exclusion chromatography (SEC; Sandron et al., 2015) it is not recommended, since acidification may result in drastic alterations of the molecular structure and confirmation of DOM molecules (Dryer et al., 2008; Pace et al., 2012). When optical properties of DOM are to be addressed and immediate sample analysis is not possible, freezing samples may constitute an appropriate preservation method. For freezing various effects on chromophoric DOM

52 composition, as well as on bulk DOC and dissolved organic nitrogen (DON) concentration have 53 been observed so far (Fellman et al., 2008; Otero et al., 2007; Peacock et al., 2015; Spencer et 54 al., 2007; Thieme et al., 2016). For instance, Fellman et al. (2008) reported that DOC and DON 55 concentration decreased due to freezing, whereas Peacock et al. (2015) reported that DOC 
concentration in peatland samples was mostly unaffected by freezing. Similarly, Otero et al.

57 (2007) did not observe effects of freezing for sediment pore water samples in an estuary.

58 Previous findings on fluorescence and absorbance properties of DOM were likewise

59 inconsistent, reporting either no effects (Otero et al., 2007), variable responses (Spencer et al.,

60 2007) or sometimes strong effects (Fellman et al., 2008; Peacock et al., 2015; Thieme et al.,

61 2016) of freezing. Thereby factors like freezing and/or thawing temperature (Chen et al. 2016,

62 Xue et al. 2015), ionic strength (Müller et al. 2011) and DOC concentration (Fellman et al. 2008,

63 Thieme et al. 2016) and DOM composition influence the physico-chemical processes during

64 freezing and thawing and thus may explain the various results observerd in literature. Size

65 exclusion chromatography (SEC) can be used to determine bulk DOC and DON concentration

66 and DOM composition, in particular the $\mathrm{C}: \mathrm{N}$ ratio and the distribution of DOC and DON in

67 different molecule size classes of DOM (Huber et al., 2011). SEC applied in parallel with analysis

68 of optical properties enables to detect changes of DOM composition and concentration

69 (Graeber et al. 2012a; Graeber et al., 2015; Heinz et al., 2015). While acidification affects size

70 fractionation with SEC (Sandron et al. 2015) and is not a suitable preservation method for this

71 analysis, the effects of freezing and cold storage at $4{ }^{\circ} \mathrm{C}$ on DOM size fractions determined with

72 SEC have not been investigated yet at least in freshwater samples. For salt water from the Baltic

73 sea no freezing effects were detected (Müller et al. 2011). However, the sometimes strong

74 effects of freezing on spectral DOM properties (Fellman et al., 2008; Peacock et al., 2015;

75 Thieme et al., 2016) indicate structural DOM alterations and suggest that SEC fractioning may

76 be likewise vulnerable to freezing. Thieme et al. (2016) demonstrated that even if bulk 
77 concentration is not affected by fast freezing with liquid nitrogen, alterations of DOM structure 87 geographic regions.

\section{Methods} and hence optical properties cannot be precluded.

In order to present a recommendation for storage and preservation of DOM samples for later SEC analysis as well as fluorescence and absorbance analysis, this study aims to evaluate the effects of freezing and cold storage on bulk DOC and DON concentration and SEC fractions. To account for differences in DOM composition we analyzed storage effects for three different sample types (freshwater DOM, leaf litter leachate, peatland pore water). To assess also the effects of freezing on DOC and DON concentration and SEC fractions for a set of different samples of the same sample type, but covering a range of DOM concentrations, we analyzed a set of peatland pore water samples from two oligotrophic nutrient poor bogs in different

We hypothesized that leaf leachates are more vulnerable to storage and freezing than lake samples due to the more 'labile' nature of leachate samples. The other way around, we expect that the peatland pore water samples constituting a less reactive humic sample type behave more or less conservative, independent from the geographical region where they derive from and independent of DOM concentration. In our study we aim to give a recommendation for storage and sample preservation for three different types of natural samples.

\subsection{Sampling and preparation of the leaf leachate}

To test the effects of cold storage and freezing on different types of DOM samples we used water from Lake Müggelsee $\left(52.446^{\circ} \mathrm{N}, 13.640^{\circ} \mathrm{E}\right)$. For lake details see Recknagel et al., 2016) 
representing a freshwater DOM source (hereafter referred to as lake sample). The leaf leachate from Phragmites australis grown in an inundated peatland 'Polder Stangenhagen' south of 100 Berlin $(52.199,13.086)$ represents a purely terrestrial, but microbially unaltered, 'fresh' DOM source (hereafter referred to as leachate sample). The lake sample was taken at the lakeshore of Lake Müggelsee and filtered with a $0.45 \mu \mathrm{m}$ cellulose acetate syringe filter (Sartorius). To prepare the leaf leachate the following leaching procedure was performed: About $50.0 \mathrm{~g}$ air104 dried plant material of Phragmites australis was placed in $2 \mathrm{~L}$ polyethylene bottles. The plant 105 material consisted mainly of leaves which were cut in 5-10 cm pieces to improve handling 106 before leaching. $1.5 \mathrm{~L}$ of $1.5 \mathrm{mM} \mathrm{NaCl}$ solution was added to the bottle resulting in complete 107 inundation of the plant material. The bottle was closed and stored at room temperature with occasional manual agitation over 24 hours. After leaching the resulting leachate was filtered with a $0.45 \mu \mathrm{m}$ cellulose acetate syringe filter (Sartorius). The filters were always rinsed with $100 \mathrm{ml}$ deionized water and preconditioned with $20 \mathrm{ml}$ sample to minimize filter effects.

Lake and leachate samples had similar DOC and DON concentrations but differed in DOC and 112 DON SEC-fractions and optical properties (Table 1). Leachate samples were characterized by 113 higher contributions of low-molecular weight DOC ( $\left.\mathrm{DOC}_{\mathrm{LMwS}}\right)$, higher aromaticity $\left(\mathrm{SUVA}_{254}\right)$ and 114 less contribution of recently, microbial produced DOM and more terrestrial derived sources (FI, $115 \beta: \alpha)$ compared to the lake sample.

Additionally, pore water samples from oligotrophic acidic ombotrophic peatlands (bogs,

117 hereafter referred to as peatland samples) located in two different geographical regions in 118 Scotland $\left(\mathrm{SCT} ; 3\right.$ sites: $58.397^{\circ} \mathrm{N},-3.341^{\circ} \mathrm{E} ; 58.373^{\circ} \mathrm{N},-3.960^{\circ} \mathrm{E} ; 58.376^{\circ} \mathrm{N},-3.952^{\circ} \mathrm{E} ; 5$ dialysis 119 samplers each) and Estonia (EST; 6 sites: $59.042^{\circ} \mathrm{N}, 25.520^{\circ} \mathrm{E} ; 58.977^{\circ} \mathrm{N}, 25.649^{\circ} \mathrm{E} ; 58.572^{\circ} \mathrm{N}$, 
$25.183^{\circ} \mathrm{E} ; 58.094^{\circ} \mathrm{N}, 25.044^{\circ} \mathrm{E} ; 58.084^{\circ} \mathrm{N}, 25.132^{\circ} \mathrm{E} ; 58.215^{\circ} \mathrm{N}, 27.360^{\circ} \mathrm{E} ; 52.446^{\circ} \mathrm{N}, 13.641^{\circ} \mathrm{E} ; 3$

121 dialysis samplers each) were analyzed. Peatland samples were taken using the dialysis sampler 122 technique (Hesslein, 1976). Dialysis samplers are thin Perspex plates covered by a $0.2 \mu \mathrm{m}$ 123 polysulfone membrane (HT-Tuffryn $200^{\circledR}$, Pall ${ }^{\circledR}$, Gelman Laboratory) containing 14 spaced 124 chambers filled with de-ionised water. Prior to insertion into the peat, oxygen from the 125 chamber water and the sampler material (Perspex) was displaced by degassing with nitrogen 126 for $24 \mathrm{~h}$. For that purpose samplers were stored in watertight polyvinyl chloride (PVC) vessels

127 (diameter $25 \mathrm{~cm}$ and length $80 \mathrm{~cm}$ ) filled completely with de-ionised water. After degassing, 128 vessels were sealed with airtight cups for transportation to the sampling sites. Dialysis samplers 129 were always inserted completely into the upper horizon of the peat $(0-60 \mathrm{~cm})$. The samplers 130 were used to obtain integrated pore water samples by combining the 14 chambers to a 131 composite sample for the DOM analysis. The exposure time of the samplers in the peat was at 132 least 7 days so that the concentrations of dissolved substances in the pore water could 133 equilibrate with the chamber water. After recovering and cleaning the samplers with deionized 134 water, the chamber water of the dialysis sampler was taken rapidly within a few minutes with a 135 multi-pipette (Eppendorf). Samples were transported to the lab at $4{ }^{\circ} \mathrm{C}$ and analyzed within 24 136 hours or frozen for further analysis. Samples of dialysis sampler were not $0.45 \mu \mathrm{m}$ filtrated 137 since the pore size of the membrane is about $0.2 \mu \mathrm{m}$ so that bacteria are widely excluded from 138 the samples in the chamber.

\subsection{Experimental setup and laboratory analyses}

To test the effects of cold storage and freezing, five replicate samples of lake and leachate 141 samples were measured within 24 hours (original sample) or stored for one weeks at $4^{\circ} \mathrm{C}$ in the 
142 dark (cold storage), or frozen at $-20^{\circ} \mathrm{C}$ (freezing). Additionally 5 replicate blank samples

143 (deionized water), subject to the same storage treatments as lake and leachate samples were 144 analyzed. Samples from the two different geographical regions (EST, SCT) were analyzed before

145 (original sample) and after freezing at $-20^{\circ} \mathrm{C}$, in order to test for the effects of freezing on the 146 DOC and DON concentration and SEC fractions of peatland pore water samples.

147 All samples were stored in $25 \mathrm{ml}$ polypropylene (PP) vessels (washed with $10 \% \mathrm{HCl}$ before 148 usage) during storage and analyzed at the same day after removing them from the refrigerator 149 or thawing at room temperature. The DOC and DON concentration and respective size fractions 150 we determined using size exclusion chromatography (SEC) combined with UV- and IR- organic 151 carbon detection and UV-organic nitrogen detection (Huber et al., 2011; Graeber et al., 2012a). 152 SEC enables to differentiate between DOC and DON in form of non-humic high molecular 153 weight substances of hydrophilic character (DOC ${ }_{H M w S}$, DON $\mathrm{HMws}_{\text {; }}$ e.g. polysaccharides and 154 proteins), humic-like substances $\left(\mathrm{DOC}_{\mathrm{HS}}, \mathrm{DON}_{\mathrm{HS}}\right)$ and low molecular weight neutral, hydrophilic

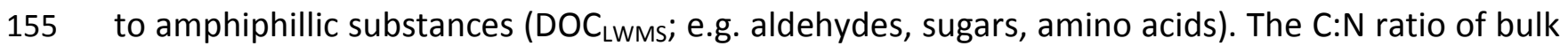
156 DOM (C: $\left.\mathrm{N}_{\mathrm{DOM}}\right)$ was calculated as the molar ratio of DOC to DON. Absorbance and fluorescence 157 properties were measured using an Aqualog spectrophotometer (Horiba, USA). An excitation 158 wavelength range from 230 to $600 \mathrm{~nm}$ with a $5 \mathrm{~nm}$ increment was used. Emission spectra were 159 collected for the wavelength range 214.1 - $619.3 \mathrm{~nm}$ with a $1.6 \mathrm{~nm}$ increment, using $1 \mathrm{~s}$ 160 integration time, a pixel bin of 4 and medium detector gain. Absorbance spectra were collected 161 from 230 to $600 \mathrm{~nm}$ in $5 \mathrm{~nm}$ steps. Absorbance and fluorescence were measured at room 162 temperature. Spectral correction was performed using the automated algorithms provided 
within the AQUALOG software (Horiba Scientific) and fluorescence intensity was normalized to Raman units using excitation wavelength of $350 \mathrm{~nm}$ (Lawaetz and Stedmon, 2009).

Following indices were calculated: From the absorbance data we calculated the SUVA 254 of DOM, which is the specific absorbance of the sample at $254 \mathrm{~nm}$ and a measure for aromaticity (Weishaar et al., 2003; Huber et al., 2011). For the peatland samples SEC was used to measure SUVA $_{254}$, since no absorbance data was available. The fluorescence data we used to calculate the humification index (HIX) (Ohno and Bro, 2006); the fluorescence index (FI), an indicator of DOM origin (more microbial (FI 1.9) or terrestrial and higher plant (FI 1.4) origins) (McKnight et al., 2001); as well as the $\beta: \alpha$ ratio, an indicator for the freshness of the material (0.6-0.8 more terrestrial input, > 1 freshly produced and released to water) (Parlanti et al., 2000).

\subsection{Statistical analyses}

All statistical analyses were performed using 'R' (2016, Version 3.3.1, The R Foundation for Statistical Computing) except for the Wilcoxon signed rank test which was performed using JMP Pro (Version 11.0.0, SAS Institute Inc. 2003). To test for the main and interaction effects of DOM source (lake, leachate) and storage treatment (cold storage at $4{ }^{\circ} \mathrm{C}$, freezing) on changes of DOC and DON concentration, we applied a permutational 2-way ANOVA (factors: DOM source, storage treatment, 10000 iterations) with interactions (based on aov(), package 'stats', R). We used a permutational 2-way ANOVA, since for DOC and DON concentration the assumptions of variance homogeneity and normal distribution of residuals were not met. To test whether storage treatment and/or DOM source affect alterations of DOM composition a permutational MANOVA (PERMANOVA) testing for the factor DOM source (lake, leachate) and storage treatment (cold storage at $4^{\circ} \mathrm{C}$, freezing) was performed (adonis() function, package 'vegan', 
185 Euclidean distance, 1000 iterations; Oksanen et al., 2015). The PERMANOVA was performed on 186 the changes of DOM composition, hence the differences between the values of the original 187 sample (measured immediately) and the samples after storage treatment and included the

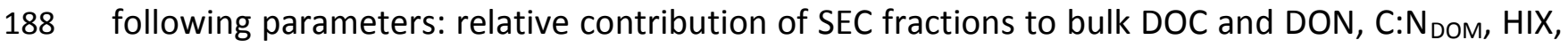
$189 \mathrm{FI}, \beta: \alpha$, and $\mathrm{SUVA}_{254}$. To test whether differences of DOC and DON concentration and DOM 190 composition between original sample and after storage treatment in lake and leachate samples 191 were significant we used the Mann-Whitney $U$ test (wilcox.test() function, package 'stats'). 192 Individual parameters of DOM composition (SEC fractions, C: $N_{\mathrm{DOM}}, \mathrm{SUVA}_{254}$ ) and as well as DOC 193 and DON concentration of the peatland samples were tested for differences before and after 194 freezing applying Wilcoxon signed rank test $(p=0.05)$.

\section{3. Results}

\subsection{DOC and DON concentration}

Permutational ANOVA revealed neither effects of DOM source nor of storage treatment on changes of DOC and DON concentration (perm. ANOVA, $p<0.05$ ). Overall, changes of DOC and

199 DON concentration in the samples due to freezing were lower than changes due to cold 200 storage. This was in particular true for leachate samples where comparatively high changes of 201 DOC and DON concentration occurred after cold storage (Fig. 1 a, b). Cold storage resulted in 202 stronger changes of DOC and DON concentration in the leachate samples (-0.31 to $1.84 \mathrm{mg} \mathrm{C}$ * $203 \mathrm{~L}^{-1} ;-11$ to $\left.64 \%\right)$ compared to lake samples (-0.23 to $0.14 \mathrm{mg} \mathrm{C} * \mathrm{~L}^{-1} ;-7$ to $4 \%$ ) (Fig. 1). Freezing 204 of lake and leachate samples resulted only in minor decreases of DOC (lake: $0.2 \mathrm{mg} \mathrm{CL^{-1 }}, \leq 5 \%$; 205 leachate: $\leq 0.3 \mathrm{mg} \mathrm{CL}^{-1}, \leq 10 \%$ ) and DON (median lake: $0.01 \mathrm{mg} \mathrm{N} \mathrm{L}^{-1}$, leachate: $0.01 \mathrm{mg} \mathrm{N} \mathrm{L}^{-1}$ ) 
concentration and were within the standard deviation from the mean for the 5 replicate original samples (Fig. 1). However, individual replicates showed strong changes of DON concentration in lake and leachate samples lake (up to $31 \%, 0.06 \mathrm{mg} \mathrm{N} \mathrm{L}^{-1}$ ) and leachate (up to $60 \%, 0.07 \mathrm{mgN} \mathrm{L}^{-1}$ ), but the observed changes were not statistically significant (Mann-Whitney $U, p>0.05)$. In peatland samples changes of DOC concentration due to freezing were lower than $10 \%$ of the initial DOC concentration for most of the peatland samples (EST: $73 \%$, SCT: 87\%). Thereby DOC concentration increased in most of the EST samples (89\%), while there was no clear trend in direction of change for DOC concentration observed in SCT samples (60\% increase, $40 \%$ decrease, Fig. 2 a). Overall, the absolute changes of DOC concentration in peatland samples were lower than $4.7 \mathrm{mg} \mathrm{C} \mathrm{L}^{-1}(<23 \%)$ for EST samples and lower than $1.6 \mathrm{mg}$ $\mathrm{CL}^{-1}(<10 \%)$ for SCT samples. However, the changes of bulk DOC concentration due to freezing were not statistically significant in EST and SCT samples (Wilcoxon signed rank test, $\mathrm{p}>0.05$; Fig. 2). In contrast, the effects of freezing on DON concentration in peatland samples differed between EST and SCT samples (Fig. 2 b). Thereby decreases of DON concentration were observed for the EST samples (Wilcoxon rank signed test, $p<0.05$ ), but not for the SCT samples (Wilcoxon rank signed test, $\mathrm{p}>0.05)$, what resulted in an increase of the molar $\mathrm{C}: \mathrm{N}_{\mathrm{DOM}}$ ratio for EST samples (Wilcoxon rank signed test, $p<0.001$ ) but not for SCT samples (Wilcoxon rank signed test, $p>0.05)$. In total, changes of DON concentration due to freezing were higher than $10 \%$ of the original bulk DON concentration for more than the half of the peatland samples (EST: $82 \%$, SCTL: $53 \%$ ) and ranged from -0.2 to $0.17 \mathrm{mg} \mathrm{N} \mathrm{L}^{-1}$. DON concentration decreased significantly in the majority of EST samples (83\%; Wilcoxon rank signed test, $p<0.05)$, while for 
227 SCT samples no significant change of DON concentration (increase 60\%, decrease $40 \%$;

228 Wilcoxon rank signed test, $\mathrm{p}>0.05$ ) was observed.

\subsection{DOM composition}

230 Storage (cold storage, freezing) resulted in changes of DOM composition, while no effect was

231 observed for DOM source (lake, leachate) (PERMANOVA). Storage treatment explained $20 \%\left(\mathrm{R}^{2}\right)$

232 of the variance significantly (PERMANOVA, $\mathrm{p}<0.0001$ ). In particular for $\mathrm{DOC}_{\mathrm{HS}}$ and $\mathrm{DOC}_{\mathrm{HMws}}$

233 (Fig. 3 a, c), C:N $\mathrm{N}_{\text {DOM }}$ (Fig. 3 d) and $\beta: \alpha$ (Fig. 4 b) and HIX (Fig. 4 c) strong changes were observed

234 after cold storage. SEC fractions were stronger affected by cold storage than by freezing (Fig. 3

$235 \mathrm{a}-\mathrm{c})$. Overall there was no evidence for effects of freezing on DOC and DON SEC fractions for

236 lake and leachate samples (Mann Whitney $U$ test, $p>0.05$; Fig. 3). Changes of contributions of

237 DOC and DON SEC fractions after cold storage were only significant for DOC $_{\text {HMws }}$ in leachate

238 samples and $\mathrm{DON}_{\mathrm{HS}}$ in lake samples (Mann Whitney $\mathrm{U}$ test, $\mathrm{p}>0.05$ ). In general changes of DOC

239 SEC fractions were more variable in leachate samples compared to lake samples (Fig. 2 a - d). In

240 the peatland samples significant changes of DOC in the individual SEC fractions were observed

241 for EST and SCT samples (Wilcoxon signed rank test, $p>0.05$; Fig. 5). Thereby in EST samples

$242 \mathrm{DOC}_{\mathrm{HS}}$ as well as $\mathrm{DOC}_{\mathrm{HMws}}$ decreased and $\mathrm{DOC}_{\mathrm{LM} w s}$ increased, whereas in the SCT samples

$243 \mathrm{DOC}_{\mathrm{HMws}}$ decreased and $\mathrm{DOC}_{\mathrm{HS}}$ increased (Wilcoxon signed rank test, $\mathrm{p}<0.05$ ). Overall changes

244 were stronger in EST samples compared to SCT samples (Fig. 5). Optical properties represented

245 by $\mathrm{HIX}, \mathrm{FI}, \beta: \alpha$ and SUVA 254 in lake and leachate samples were in most cases stronger affected

246 by storage in leachate compared to lake samples (Fig. 3 a - d). Thereby changes of FI and $\beta: \alpha$

247 were not statistically significant (Mann Whitney $U, p>0.05$ ), even though comparatively high

248 changes of $\beta: \alpha$ were observed in leachate samples after one week of storage at $4^{\circ} \mathrm{C}$ (Fig. 3 b). 
249 Cold storage resulted in significant changes of HIX in lake and leachate samples (Mann Whitney

$250 U, p<0.05)$. SUVA 254 was not affected by cold storage but decreased in leachate samples after

251 freezing (Mann Whitney $U, p<0.05$ ). In the EST pore water samples SUVA 254 did not change

252 significantly (average change: $0.10 \pm 0.23 \mathrm{~L} \mathrm{mg} \mathrm{C} \mathrm{m}^{-1}$; Wilcoxon rank signed test, $\mathrm{p}>0.05$ ), while

253 in the SCT samples SUVA 254 was slightly increased after freezing (up to $17 \%, 0.5 \mathrm{~cm}^{-1}$; average

254 change $0.16 \pm 0.22 \mathrm{~L} \mathrm{mg} \mathrm{C} \mathrm{m}^{-1}$; Wilcoxon rank signed test $\left.\mathrm{p}<0.05\right)$.

\section{4. Discussion}

256 We have selected three different types of DOM samples to test if freezing and storage at $4^{\circ} \mathrm{C}$

257 for one week alter DOC and DON concentration and DOM composition. We expected larger

258 effects on leaf leachates compared to lake and peatland samples, since leachate DOM is not

259 microbially processed so far, and thus supposed to be of more labile nature, i.e. more

260 vulnerable to cold storage and freezing.

261 In accordance with our expectations effects on DOC and DON concentration were stronger

262 for leachate than for lake samples, in particular after one week storage at $4^{\circ} \mathrm{C}$ with changes up

263 to $64 \%$ of the initial DOC concentration in leachate samples. The change in optical properties

264 towards a lower degree of humification ( $\mathrm{HIX}$ ) and aromaticity (SUVA 254 ), a higher contribution

265 of recently produced fluorescent $\operatorname{DOM}(\beta: \alpha)$, together with an increase of non-humic high

266 molecular weight substances ( $\mathrm{DOC}_{\mathrm{HMws}}$ ) in the leachate sample after cold storage point to a

267 microbial DOM as source for variation in DOC concentration. This is supported by findings of

268 Wang et al. (2007) who showed that large fractions of bacteria cannot be retained by $0.45 \mu \mathrm{m}$

269 pore size filters. In accordance with previous studies, which reported only minor changes of 
270 DOC concentration due to short-term storage for freshwater samples (Peacock et al. 2015,

271 Carter et al. 2012) the lake samples were not affected by cold storage.

272 After freezing only minor changes of DOC and DON compared to the DOC and DON

273 concentrations in the original sample were observed for lake $(\leq 5 \%)$ and leachate $(\leq 10 \%)$

274 samples, as well as for the majority of peatland samples ( $<10 \%)$. Overall, changes of DON

275 concentration after freezing were likewise low in lake and leachate samples (median: <

276 detection limit, $0.01 \mathrm{mg} \mathrm{N} \mathrm{L}^{-1}$ ).

277 Our findings on the effects of freezing on DOC and DON concentration in lake and leachate

278 samples are in accordance with the findings of Fellman et al. (2008) who observed no, or only

279 minor changes of DOC concentration after freezing for samples with low DOC concentration $(<$

$2805 \mathrm{mg} \mathrm{L}^{-1}$ ). However, although no overall change of DON concentration was observed,

281 sometimes strong responses to freezing occurred for individual replicates.Although these

282 changes were not statistically significant, we recommend that care should be taken for low

283 initial DON concentration (lake: $0.19 \pm 0.00 \mathrm{mg} \mathrm{N} \mathrm{L}^{-1}$, leachate: $0.13 \pm 0.01 \mathrm{mg} \mathrm{N} \mathrm{L}^{-1}$ ). For stream

284 samples and a range of terrestrial DOM sources, the magnitude of the effects of freezing can

285 strongly depend on DOC concentration (Fellman et al., 2008; Thieme et al., 2016). Fellman et al.

286 (2008) for example, reported decreasing DOC concentration as a result of abiotic particle

287 formation during freezing. This is in contrast to our results for peatland samples, since despite

288 high initial DOC concentration $\left(7-40 \mathrm{mg} \mathrm{C} \mathrm{L}^{-1}\right)$, changes of DOC concentration were lower than

$28910 \%$ in $70 \%$ of the peatland samples and overall not significant. This is in accordance with

290 results from Peacock et al., (2015), who did not report a relationship between DOC

291 concentration and the effects of freezing for surface water samples from peatlands. However, 
292 in EST samples but not in SCT samples DON concentration and C:N $\mathrm{N}_{\text {DOM }}$ were altered due 293 freezing. Moreover, for samples from both regions effects of freezing on SEC fractions were 294 observed, whereby these effects were more pronounced in EST samples. In particular the 295 strong increases in low molecular weight $\mathrm{DOC}$ ( $\mathrm{DOC}_{\mathrm{LMwS}}$ ) ongoing with decreases in high 296 molecular weight $\mathrm{DOC}\left(\mathrm{DOC}_{\mathrm{HS}}\right.$ and $\mathrm{DOC}_{\mathrm{HMws}}$ ) indicate, that freezing may result in physical 297 breakdown of high molecular weight substances into low molecular weight substances. 298 Previously it has been shown that DOM preferentially concentrates in the remaining liquid 299 phase during freezing (Belzile et al., 2002; Xue et al., 2015) and that concentration of DOM can 300 affect its macromolecular configuration (Ghosh and Schnitzer, 1980). Differences in partitioning 301 and concentration behavior were observed for individual DOM fractions (Xue et al., 2015). 302 Hence, partitioning and concentration during freezing and thawing (Belzile et al., 2002; Xue et 303 al., 2015) could have changed size fractioning of DOM and have a lasting effect on DOM 304 composition also after complete thawing of the sample. The different responses of SEC 305 fractions to freezing in lake and leachate with moderate DOC concentrations compared to 306 peatland samples with high DOC concentrations indicate that underlying processes are affected 307 by sample type and DOC concentration. Differences in the effects of freezing in peatland 308 samples from 2 different geographic regions show that magnitude and direction of change may 309 be also determined the sampling location.

310 Moreover, also the freezing temperature (Xue et al. 2015, Chen et al. 2016) or method 311 (Thieme et al. 2016) affect DOC concentration in the sample. Furthermore sampling site specific 312 sample characteristics as ionic strength (Mueller et al. 2011) can affect the freezing behaviour 313 of a sample, and the erichment of DOM in ice during freezing. The results of this study are 
314 therefore study and sampling site specific and may not apply to samples from other samling

315 locations, or under other freezing conditions (temperature, method).

316 Strong variations in changes of optical properties and SEC fractions after storage at $4^{\circ} \mathrm{C}$ in

317 particular for leachate samples demonstrated that the DOM composition of leachate samples is

318 more likely affected by storage than DOM composition in lake samples. Overall, DOM

319 composition in lake and leachate samples was affected stronger by cold storage than by

320 freezing, whereby only $\mathrm{HIX}$ and SUVA $_{254}$ were altered due to freezing. In accordance with

321 previous studies (Peacock et al., 2015; Thieme et al., 2016) we do not recommend freezing of

322 samples for later analysis of optical properties.

323 5. Conclusions

Overall, freezing, seemed to constitute an appropriate preservation method for the analysis

325 of bulk DOC concentration with SEC for lake, leachate and peatland samples analyzed here, but

326 maybe not apply for samples from other geographical regions or preserved under other

327 freezing conditions. If initial DOC concentrations in samples are high (> $\left.7 \mathrm{mg} \mathrm{C} \mathrm{L}^{-1}\right)$ e.g. in peat

328 samples, freezing can affect the individual SEC fractions as well as DON concentration and

329 should therefore be avoided. Likewise alterations of optical properties, in particular for HIX and

330 SUVA $_{254}$ due to freezing cannot be precluded and we recommend immediate analysis of

331 samples for spectral analysis. Further research should evaluate the effects of freezing on SEC

332 fractions of DOC and DON in different types of lake, leachate and pore water samples and with

333 different DOC and DON concentrations in order to develop a general guidance for sample

334 preparation of freshwater DOM. 


\section{Acknowledgement}

336 We thank Sarah Schell, Mirjam Schneider and Thomas Rossoll for support in field work and

337 laboratory analyses. This research was conducted within the project DONCOPRA (PU 136/7-1),

338 we want to thank German Science Foundation (DFG) for funding the project. 
340

341

342

343

344

345

346

347

348

349

350

351

352

353

354

355

356

357

\section{References}

Belzile, C., Gibson, J.A.E., Vincent, W.F., 2002. Colored dissolved organic matter and dissolved organic carbon exclusion from lake ice: Implications for irradiance transmission and carbon cycling. Limnology and Oceanography 47, 1283-1293.

Chen, J., Xue, S., Lin, Y., Wang, C., Wang, Q., Han, Q., 2016. Effect of freezing-thawing on dissolved organic matter in water. Desalination and Water Treatment 57 (37), 1723017240.

Dryer, D.J., Korshin, G.V., Fabbricino, M., 2008. In Situ Examination of the Protonation Behavior of Fulvic Acids Using Differential Absorbance Spectroscopy. Environmental Science and Technology 42, 6644-6649.

Fellman, J.B., D'Amore, D.V., Hood, E., 2008. An evaluation of freezing as a preservation technique for analyzing dissolved organic C, N and P in surface water samples. Science of the Total Environment 392, 305-12.

Gao, Y., Yan, M., Korshin, G.V., 2015. Effects of lonic Strength on the Chromophores of Dissolved Organic Matter. Environmental Science and Technology 49, 5905-5912.

Ghosh, K., Schnitzer, M., 1980. Macromolecular structures of humic substances. Soil Science 129 (5), 266-276.

Giesy, J.P., Briese, L.A., 1978. Particulate formation due to freezing humic waters. Water Resource Research 14, 542-544. 
Graeber, D., Boëchat, I.G., Encina-Montoya, F., Esse, C., Gelbrecht, J., Goyenola, G., Gücker, B., Heinz, M., Kronvang, B., Meerhoff, M., Nimptsch, J., Pusch, M.T., Silva, R.C.S., von Schiller, D., Zwirnmann, E., 2015. Global effects of agriculture on fluvial dissolved organic matter. Scientific Reports 5, 16328.

Graeber, D., Gelbrecht, J., Pusch, M.T., Anlanger, C., von Schiller, D., 2012a. Agriculture has changed the amount and composition of dissolved organic matter in Central European headwater streams. Science of the Total Environment 438, 435-446.

Graeber, D., Gelbrecht, J., Kronvang, B., Gücker, B., Pusch, M., Zwirnmann, E., 2012b. Technical Note: Comparison between a direct and the standard, indirect method for dissolved organic nitrogen determination in freshwater environments with high dissolved inorganic nitrogen concentrations. Biogeosciences 9 (11), 4873-4884.

Heinz, M., Graeber, D., Zak, D., Zwirnmann, E., Gelbrecht, J., Pusch, M.T., 2015. Comparison of organic matter composition in agricultural versus forest affected headwaters with special emphasis on organic nitrogen. Environmental Science and Technology 49, 2081-2090.

Hesslein, R.H. 1976. An in situ sampler for close interval pore water studies. Limnology and Oceanography 21: 912-914

Huber, S.A., Balz, A., Abert, M., Pronk, W., 2011. Characterisation of aquatic humic and nonhumic matter with size-exclusion chromatography - organic carbon detection - organic nitrogen detection (LC-OCD-OND). Water Research 45, 879-885.

Lawaetz, A.J., Stedmon, C.A., 2009. Fluorescence intensity calibration using the Raman scatter peak of water. Applied Spectroscopy 63, 936-940. 
Leenheer, J.A., Croué, J.-P., 2003. Peer Reviewed: Characterizing Aquatic Dissolved Organic Matter. Environmental Science and Technology 37, 18A-26A.

McKnight, D.M., Boyer, E.W., Westerhoff, P.K., Doran, P.T., Kulbe, T., Andersen, D.T., 2001. Spectrofluorometric characterization of dissolved organic matter for indication of precursor organic material and aromaticity. Limnology and Oceanography 46, 38-48.

Müller, S., Vähätalo, A.V., Granskog, M.A., Autio, R., Kaartokallio, H., 2011. Behaviour of dissolved organic matter during sea ice formation of natural and artificially grown Baltic Sea ice. Annals of Glaciology 52 (57), 233-241.

Ohno, T., Bro, R., 2006. Dissolved Organic Matter Characterization Using Multiway Spectral Decomposition of Fluorescence Landscapes. Soil Science Society of America Journal 70, 2028.

Oksanen, J., Blanchet, F.G., Kindt, R., Legendre, P., Minchin, P.R., O’Hara, R.B., Simpson, G.L., Solymos, P., Stevens, M.H.H., Wagner, H., 2015. vegan: Community Ecology Package.

Otero, M., Mendonça, A., Válega, M., Santos, E.B.H., Pereira, E., Esteves, V.I., Duarte, A., 2007. Fluorescence and DOC contents of estuarine pore waters from colonized and noncolonized sediments: Effects of sampling preservation. Chemosphere 67, 211-220.

Pace, M.L., Reche, I., Cole, J.J., Fernández-Barbero, A., Mazuecos, I.P., Prairie, Y.T., 2012. pH change induces shifts in the size and light absorption of dissolved organic matter. Biogeochemistry 108, 109-118. 
Parlanti, E., Worz, K., Geoffroy, L., Lamotte, M., 2000. Dissolved organic matter fluorescence spectroscopy as a tool to estimate biological activity in a coastal zone submitted to anthropogenic inputs. Organic Geochemistry 31, 1765-1781.

Parr, T.B., Cronan, C.S., Ohno, T., Findlay, S.E.G., Smith, S.M.C., Simon, K.S., 2015. Urbanization changes the composition and bioavailability of dissolved organic matter in headwater streams. Limnology and Oceanography 60(3), 885-900.

Peacock, M., Freeman, C., Gauci, V., Lebron, I., Evans, C.D., 2015. Investigations of freezing and cold storage for the analysis of peatland dissolved organic carbon (DOC) and absorbance properties. Environmental Science: Processes and Impacts 17(7), 1290-1301

Petrone, K.C., Richards, J.S., Grierson, P.F., 2009. Bioavailability and composition of dissolved organic carbon and nitrogen in a near coastal catchment of south-western Australia. Biogeochemistry 92(1-2), 27-40.

Recknagel, F., Adrian, R., Köhler, J., Cao, H., 2016. Threshold quantification and short-term forecasting of Anabaena, Aphanizomenon and Microcystis in the polymictic eutrophic Lake Müggelsee (Germany) by inferential modelling using the hybrid evolutionary algorithm HEA. Hydrobiologia 778, 61-74.

Sandron, S., Rojas, A., Wilson, R., Davies, N.W., Haddad, P.R., Shellie, R.A., Nesterenko, P.N., Kelleher, B.P., Paull, B., 2015. Chromatographic methods for the isolation, separation and characterisation of dissolved organic matter. Environmental Science: Processes and Impacts 17, 1531-1567. 
419 Schneider-Zapp, K., Salter, M.E., Mann, P.J., Upstill-Goddard, R.C., 2013. Technical Note:

420 Comparison of storage strategies of sea surface microlayer samples. Biogeosciences 10,

$421 \quad$ 4927-4936.

422 Spencer, R.G.M., Bolton, L., Baker, A., 2007. Freeze/thaw and pH effects on freshwater

423 dissolved organic matter fluorescence and absorbance properties from a number of UK

$424 \quad$ locations. Water Research 41, 2941-2950.

425 Thieme, L., Graeber, D., Kaupenjohann, M., Siemens, J., 2016. Fast-freezing with liquid nitrogen

426 preserves bulk dissolved organic matter concentrations, but not its composition.

427 Biogeosciences Discussions 2016, 1-20.

428 Weishaar, J.L., Aiken, G.R., Bergamaschi, B.A., Fram, M.S., Fujii, R., Mopper, K., 2003. Evaluation

429 of Specific Ultraviolet Absorbance as an Indicator of the Chemical Composition and

430 Reactivity of Dissolved Organic Carbon. Environmental Science and Technology 37, 4702-

$431 \quad 4708$.

432 Xue, S., Wen, Y., Hui, X., Zhang, L., Zhang, Z., Wang, J., Zhang, Y., 2015. The migration and

433 transformation of dissolved organic matter during the freezing processes of water. Journal of

434 Environmental Sciences (China) 27, 168-178.

435 
436 Tables

437 Table 1. Brief summary of sample composition including optical properties and DOC and DON SEC 438 fractions of the original lake $(n=5)$, leachate $(n=5)$ and peatland samples (peat-EST: $n=18 ;$ SCT: $n=15$ ).

439 The contributions of the respective SEC fractions are given in percentage of bulk DON and DOC. SUVA 254

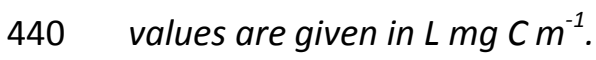

\begin{tabular}{llllllll}
\hline Source & DOC $_{H S}$ & DOC $_{H M W S}$ & DOC $_{L M W S}$ & DON $_{H S}$ & DON $_{H M W S}$ & SUVA $_{254}$ & $\mathrm{C:N}_{\text {DOM }}$ \\
\hline \hline lake & $74.7(1.4)$ & $9.5(0.3)$ & $15.6(1.5)$ & $80.7(0.7)$ & $19.3(0.7)$ & $2.3(0.0)$ & $9.0(0.2)$ \\
leachate & $72.3(2.8)$ & $3.1(0.3)$ & $25(3.0)$ & $95.7(0.7)$ & $4.3(0.7)$ & $3.3(0.1)$ & $7.4(0.5)$ \\
peat-EST & $94.2(2.9)$ & $5.1(1.4)$ & $0.6(1.8)$ & $76.3(8.7)$ & $23.7(8.7)$ & $3.4(0.4)$ & $35.9(6.8)$ \\
peat-SCT & $76.1(5.2)$ & $7.6(1.5)$ & $16.2(4.8)$ & $74.6(5.7)$ & $25.4(5.7)$ & $3.6(0.6)$ & $51.1(11.4)$ \\
\hline
\end{tabular}

441

442 Table 1 (continued).

\begin{tabular}{llll}
\hline Source & HIX & FI & $\beta: \alpha$ \\
\hline \hline lake & $0.9(0.0)$ & $1.6(0.0)$ & $0.8(0.0)$ \\
leachate & $0.8(0.0)$ & $1.4(0.0)$ & $0.5(0.0)$
\end{tabular}

443

444 


\section{$445 \quad$ Figures}

446 Figure 1. Total differences of DOC (a) and DON (b) concentration after cold storage $\left.4{ }^{\circ} \mathrm{C}\right)$ and freezing ($44720{ }^{\circ} \mathrm{C}$ ) relative to the mean of original sample concentration (gray solid line). Data is shown for lake 448 samples (white boxes) and leachate samples (light gray boxes). Dashed lines represent the standard 449 deviation from the mean of the initial concentration for lake (dashed line) and leachate (dotted line) 450 samples.

451 Figure 2. Relative changes of DOC (a) and DON (b) concentration and molar C:N ratio of DOM (c) after 452 freezing for peatland samples from Estonia (white) and Scotland (gray). Changes are shown as 453 percentage of the initial concentration in the original sample. Asterisks mark significant differences to 454 the initial concentration in the original sample (Wilcoxon signed rank test, $p=0.05, p: *<0.05, * * *<$ 455 0.001).

Figure 3. Total changes of the relative contributions SEC fractions to bulk DOM $(a-c)$ and changes of molar $C: N_{D O M}(d)$ after one week of cold storage $\left(4{ }^{\circ} \mathrm{C}\right)$ and freezing $\left(-20^{\circ} \mathrm{C}\right)$ relative to the mean of initial values in the original sample (gray solid zero line). White boxes represent lake samples and grey boxes leachate samples. Dashed lines represent the standard deviation from the mean of the initial concentration for lake (dashed line) and leachate (dotted line) samples. Asterisks mark significant differences to the initial concentration in the original sample (Mann-Whitney $U$ test, $p=0.05$ ).

462 Figure 4. Total changes of optical properties, FI (a), freshness index $8: \alpha$, HIX and SUVA ${ }_{254}$ after one week 463 of cold storage $\left(4{ }^{\circ} \mathrm{C}\right)$ and freezing $\left(-20^{\circ} \mathrm{C}\right)$ relative to the mean of initial values in the original sample 464 (gray solid zero line). White boxes represent lake samples and grey boxes leachate samples. Dashed lines 465 represent the standard deviation from the mean of the initial concentration for lake (dashed line) and 466 leachate (dotted line) samples. Asterisks mark significant differences to the initial concentration in the 467 original sample (Mann-Whitney $U$ test, $p=0.05$ ).

468 Figure 5. Total changes of DOC in the humic-like (HS), non-humic high molecular weight (HMWS) and low 469 molecular weight (LMWS) SEC fraction after freezing. White boxes represent peatland samples from 470 Estonia, grey boxes samples from Scotland. Asterisks mark significant differences to the initial 471 concentration in the original sample (Wilcoxon signed rank test, $p=0.05, p:{ }^{*}<0.05$ ). 

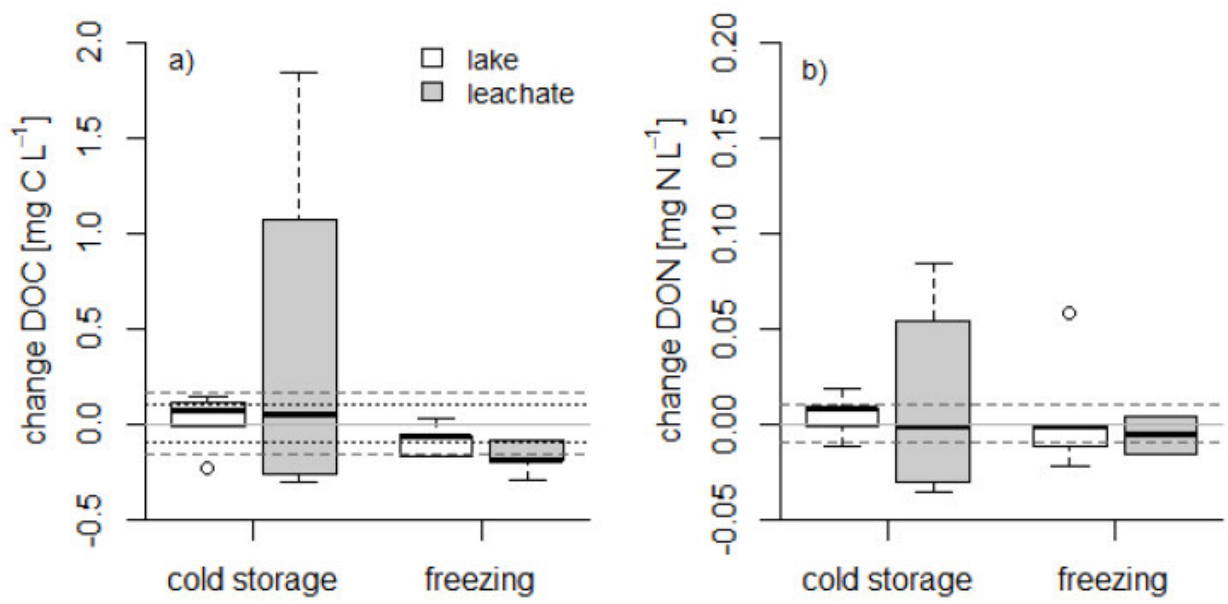

Figure 1. Total differences of DOC (a) and DON (b) concentration after cold storage $\left(4^{\circ} \mathrm{C}\right)$ and freezing ($20{ }^{\circ} \mathrm{C}$ ) relative to the mean of original sample concentration (gray solid line). Data is shown for lake samples (white boxes) and leachate samples (light gray boxes). Dashed lines represent the standard deviation from the mean of the initial concentration for lake (dashed line) and leachate (dotted line) samples.
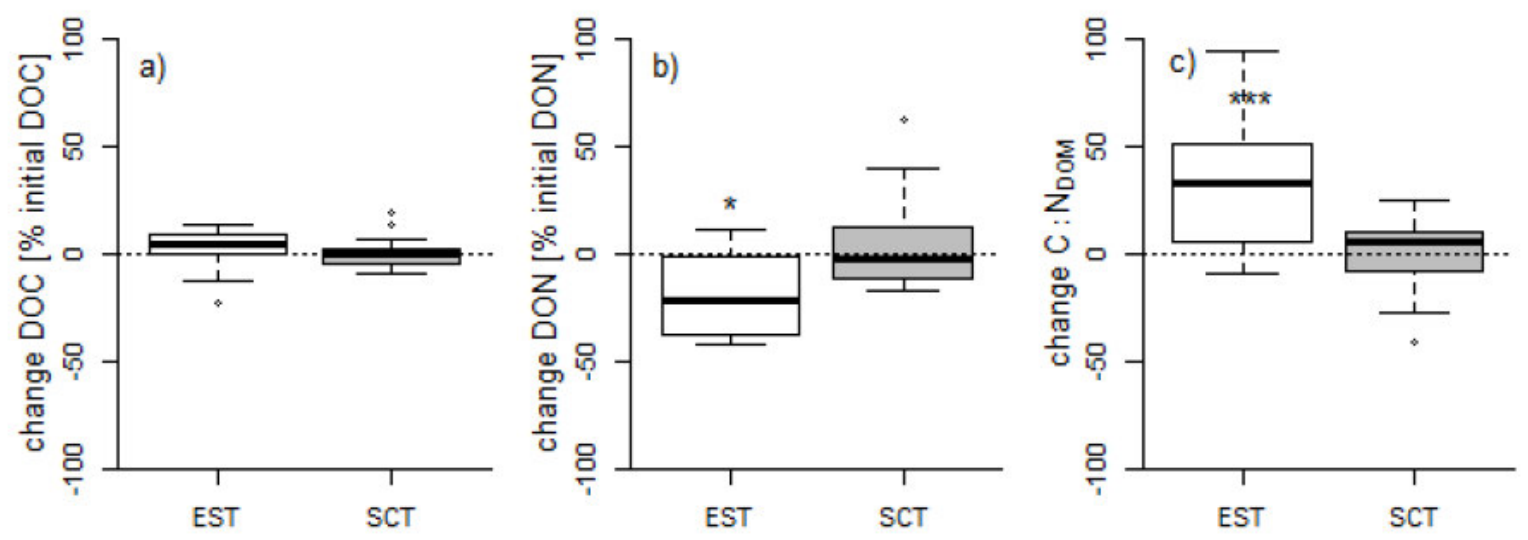

Figure 2. Relative changes of DOC (a) and DON (b) concentration and molar C:N ratio of DOM (c) after freezing for samples from Estonia (white) and Scotland (gray). Changes are shown as percentage of the initial concentration of the original sample. Asterisks mark significant differences to the initial values in original sample (Wilcoxon signed rank test, $p=0.05, p:{ }^{*}<0.05,{ }^{* *}<0.001$ ). 

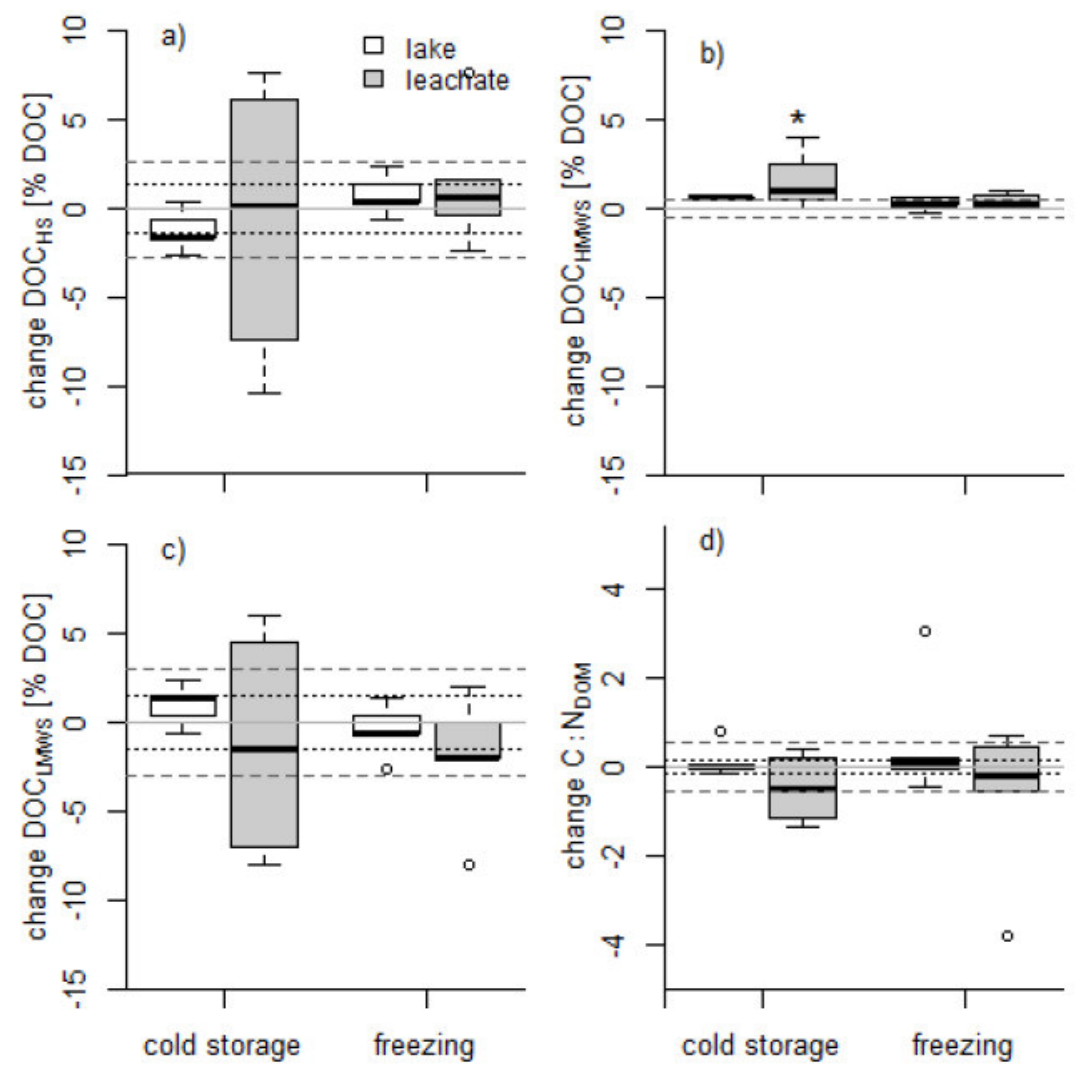

Figure 3. Total changes of the relative contributions SEC fractions to bulk DOM $(a-c)$ and changes of molar C: $N_{\text {DOM }}(d)$ after one week of cold storage $\left(4{ }^{\circ} \mathrm{C}\right)$ and freezing $\left(-20{ }^{\circ} \mathrm{C}\right)$ relative to the mean of initial values in the original sample (gray solid zero line). White boxes represent lake samples and grey boxes leachate samples. Dashed lines represent the standard deviation from the mean of the initial concentration for lake (dashed line) and leachate (dotted line) samples. Asterisks mark significant differences to the initial values in original sample (Mann-Whitney $U$ test, $p=0.05$ ).

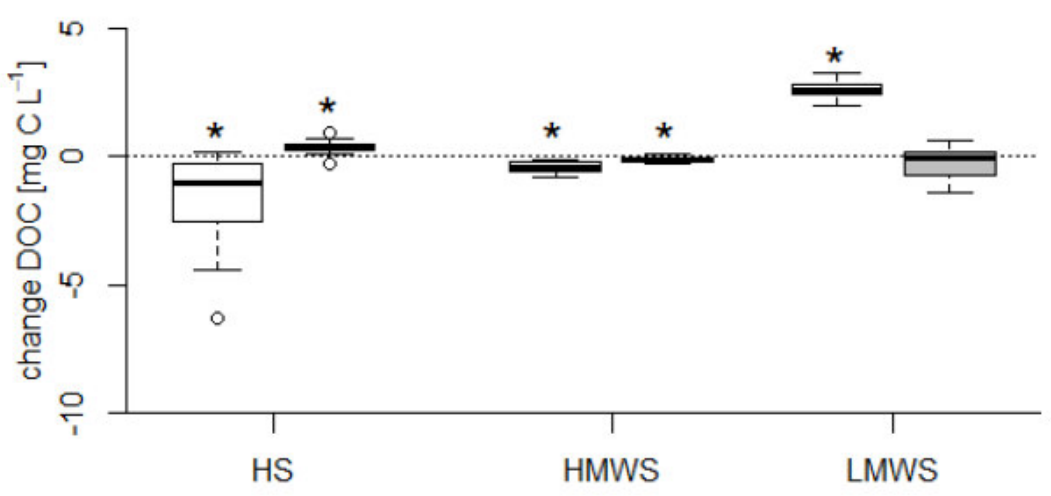

Figure 5. Total changes of DOC in the humic-like (HS), non-humic high molecular weight (HMWS) and low molecular weight (LMWS) SEC fraction after freezing. White boxes represent samples from Estonia, grey boxes samples from Scotland. Asterisks mark significant differences to the initial values in original sample (Wilcoxon signed rank test, $p=0.05, p:{ }^{*}<0.05$ ). 